\title{
Precision medicine for locally advanced breast cancer: frontiers and challenges in Latin America
}

\author{
Joseph A Pinto', César H Saravia ${ }^{1}$, Claudio Flores ${ }^{1}$, Jhajaira M Araujo ${ }^{1}$, David Martínez ${ }^{2}$, Luis J Schwarz ${ }^{3}$, Alberto $^{1}$ Casas ${ }^{4}$, Leny \\ Bravo $^{4}$, Jenny Zavaleta ${ }^{4}$, Brigitte Chuima ${ }^{5}$, Hober Alvarado $^{6}$, Ricardo Fujita ${ }^{7}$ and Henry L Gómez ${ }^{3,8}$
}

\author{
1Unidad de Investigación Básica y Traslacional, Oncosalud-AUNA, Lima 15036, Perú \\ ${ }^{2}$ Departamento de Radioterapia, Oncosalud-AUNA, Lima 15036, Perú \\ ${ }^{3}$ Departamento de Medicina Oncológica, Oncosalud-AUNA, Lima 15036, Perú \\ ${ }^{4}$ Escuela Profesional de Medicina Humana, Universidad Privada San Juan Bautista, Lima 15067, Perú \\ 5Laboratorio Clínico, Clínica Delgado, Lima 15074, Perú \\ ${ }^{6}$ Facultad de Ciencias Biológicas, Universidad Nacional San Luis Gonzaga de Ica, Ica 11004, Perú \\ ${ }^{7}$ Centro de Genética y Biología Molecular, Universidad de San Martín de Porres, Lima 15024, Perú \\ ${ }^{8}$ Departamento de Medicina Oncológica, Instituto Nacional de Enfermedades Neoplásicas, 15038, Perú
}

Correspondence to: Joseph A Pinto. Email: jpinto@gecoperu.org

\begin{abstract}
Advances in high-throughput technologies and their involvement in the 'omics' of cancer have made possible the identification of hundreds of biomarkers and the development of predictive and prognostic platforms that model the management of cancer from evidence-based medicine to precision medicine. Latin America (LATAM) is a region characterised by fragmented healthcare, high rates of poverty and disparities to access to a basic standard of care not only for cancer but also for other complex diseases. Patients from the public setting cannot afford targeted therapy, the facilities offering genomic platforms are scarce and the use of high-precision radiotherapy is limited to few facilities. Despite the fact that LATAM oncologists are well-trained in the use of genomic platforms and constantly participate in genomic projects, a medical practice based in precision oncology is a great challenge and frequently limited to private practice. In breast cancer, we are waiting for the results of large basket trials to incorporate the detection of actionable mutations to select targeted treatments, in a similar way to the management of lung cancer. On the other hand and paradoxically, in the 'one fit is not for all' era, clinical and genomic studies continue grouping our patients under the single label 'Latin American' or 'Hispanic' despite the different ancestries and genomic backgrounds seen in the region. More regional cancer genomic initiatives and public availability of this data are needed in order to develop more precise oncology in locally advanced breast cancer.
\end{abstract}

Keywords: locally advanced breast cancer, precision medicine, genomic platforms

Published: 22/01/2019

Received: $14 / 07 / 2018$

ecancer 2019, 13:896 https://doi.org/10.3332/ecancer.2019.896

Copyright: (c) the authors; licensee ecancermedicalscience. This is an Open Access article distributed under the terms of the Creative Commons Attribution License (http://creativecommons.org/licenses/by/3.0), which permits unrestricted use, distribution, and reproduction in any medium, provided the original work is properly cited. 


\section{Introduction}

Breast cancer is a highly prevalent malignancy causing $\approx 45,000$ deaths every year in women in Latin America (LATAM) and the Caribbean [33]. The poorest outcomes of breast cancer seen in the region contrast with the lower mortality reported in developed countries. It is a product of late stages diagnosis and deficient cancer care [46].

There are several barriers leading to inadequate cancer management in LATAM, including lack of treatment coverage, lack of access to specialised cancer care and geographical barriers, among others [24]. If access to a standard of care in LATAM patients is complicated by a series of barriers previously exposed, the approach to precision medicine is challenging and mainly limited to private practice.

Advances in genomic profiling of breast cancer have led to a deep knowledge of the mechanisms of the disease and the identification of several actionable mutations. Latin American scientists participate actively in genomic research of several cancers while oncologists in the region are well-trained to integrate genomic data into patient management. Despite these advances, the lack of approved targeted treatments (other than mTOR inhibitors and anti-HER2 agents) makes the genomic profiling of breast cancer less attractive compared with other tumours, such as lung cancer.

In this manuscript, we reviewed the status of precision medicine in LATAM and its current use in the management of locally advanced breast cancer.

\section{Breast cancer subtypes}

Since the year 2000, breast cancer has been revealed as a heterogeneous disease composed of at least four distinct molecular entities: luminal A, luminal B, HER2 and Basal-like tumours. Molecular classification of breast cancer is possible assessing four clusters of genes related to cell proliferation, Her2 signalling and luminal and basal epithelial-related genes [63, 76].

The molecular classification proposed by Perou and Sorlie was based in the evaluation of more than 500 transcripts; however, in 2009 , Parker et al [59] proposed a set of 50 'intrinsic' genes able to identify the breast cancer subtypes and with great prognostic capability. This molecular test was named PAM50 [59]. These subtypes can be inferred with immunohistochemical (IHC) assessment of oestrogen receptor, progesterone receptor and HER2 [18]. The marker Ki-67 improves the detection of luminal A tumours (these tumours present Ki-67 staining < 14\%) [22]. Luminal $\mathrm{A}$ is defined by IHC by positivity to any hormone receptor (estrogen receptor (ER) or progesterone receptor $(\mathrm{PR})$ ) negativity to HER2 and a $\mathrm{KI}-67$ staining in $<14 \%$ of tumour cells; Luminal $\mathrm{B}$ is defined by positivity to any hormone receptor and a Ki-67 staining $\geq 14 \%$; HER2 subtypes present negativity to both hormone receptors and positivity to HER2 and triple-negative breast cancers (TNBC) present negativity to both hormone receptors and HER2.

One typical feature of LATAM patients is a high prevalence of triple-negative breast cancer (up to 21.3\%) in contrast to Caucasian populations (around 9\%) [82, 86]. Subtypes identification is performed mainly by IHC in the clinical routine. The study of the epidemiology of breast cancer subtypes in LATAM is faced with heterogeneity between laboratories, antibodies and reagents used in the IHC, interpretation and most important, the assessment of Ki-67.

Regarding to the prevalence of breast cancer subtypes, distribution of HER2 and triple-negative subtypes is the most homogeneous among LATAM countries (ranging from $4.8 \%-18 \%$ and $13 \%-21.3 \%$, respectively), contrasting to frequencies of luminal $\mathrm{A}(25.8 \%-76.6 \%$ ) and luminal B tumours $(7.2 \%-46.1 \%)$ (Figure 1). Heterogeneity seen in luminal tumours could be attributed to the difficulty to discriminate luminal A from luminal B cases, where Ki-67 staining plays a major role. Yabar et al [86] evaluating a mixed cohort of patients from Peru and Uruguay, found that distribution of luminal A tumours change from $41.1 \%$ to $31.9 \%$ after the inclusion of $\mathrm{Ki}-67$ in the IHC panel to determine the breast cancer subtypes. Inclusion of $\mathrm{Ki}-67$ in the IHC panel to evaluate recently diagnosed breast tumours is relatively new and therefore in the coming years, reports about the distribution of breast cancer subtypes in LATAM will be more accurate and less heterogeneous. 


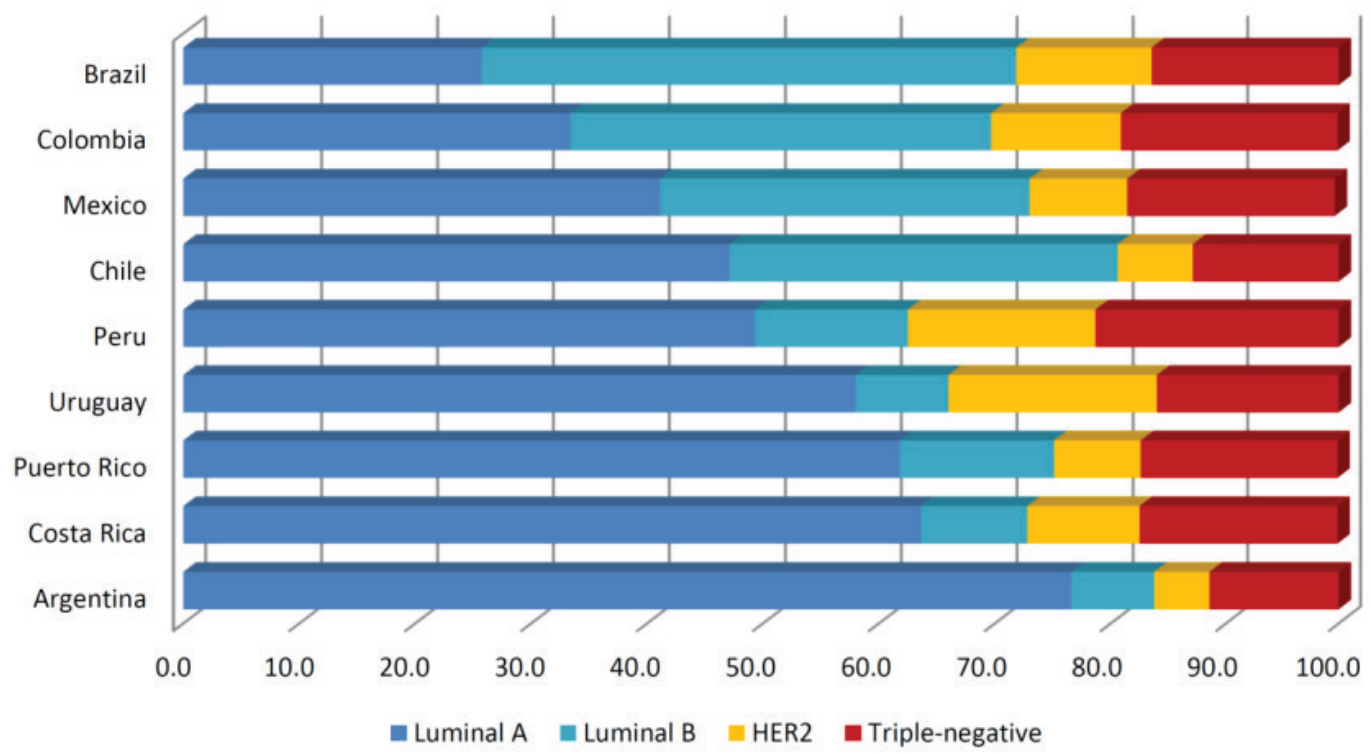

Figure 1. Distribution of breast cancer subtypes in Latin American countries (in percentages). We evaluated publications based on hospital registries. Papers with selected groups of patients were excluded (e.g. cohorts entirely composed of non-metastatic patients or operable patients). We obtained the average subtype's composition when two or more studies were reported for the same country. Papers selected were: $[1,3,12,16,20,27,54,57,61,62,66,72,77$ and 83$]$.

\section{Mutational profile of breast cancer, genomic platforms and opportunities to precision medicine}

The breast cancer genome has been deeply studied and there are several initiatives in malignancy that have revealed the mechanism of disease, mechanisms of drug resistance and potential drug targets. In addition, particular mutational patterns in the breast cancer subtypes have been found, for example, high frequencies of mutations in the PI3K/AKT pathway in luminal A tumours (>40\% of cases) and high rates of TP53 mutations in HER2 and basal-like tumours (>70\%), as shown in large genomic projects [10, 17, 60]. The public availability of these data is boosting the research of this malignancy around the globe.

Some regional initiatives have shown some molecular features of breast cancer in LATAM. In regard to mutations in PIK3CA, mutations were reported in $27 \%$ of breast cancer cases in Brazil and in $15.7 \%$ of HER2-amplified and triple negative non-metastatic cases in Peru $[21,51]$. TP53 was also studied in LATAM. In Brazil, frequency mutations in this gene are reported in $73.3 \%$ of patients, while the founder mutation TP53 p.R337H is detected in $0.3 \%$ of the general population in southern Brazil and it is responsible for $3.4-8.6 \%$ hereditary or familiar breast cancers [51, 90]. In a cohort of Peruvian patients with triple-negative breast cancer, $89 \%$ of cases bearing TP53 mutations were described [9]. In this group of patients, JAK2 and MYC amplification (12.5\% and 35\%, respectively) were recently described as alterations with the potential to be targeted to small molecules inhibitors and were statistically related with shorter survival [8,9].

A review of the most frequent mutations in breast cancer points to the potential incorporation of targeted treatments, in addition to the currently approved drugs in a high proportion of patients (Table 1).

Nowadays, there is a wide availability of genomic platforms offered to cancer profiling. Undoubtedly, the most successful model of the incorporation of genomic platforms is in the management of non-small cancer lung cancer. Regarding breast cancer, multigene assays to calculate risk scores, including, OncotypeDx, Mammaprint, Prosigna, Endopredict and others, have gained a high value and wide acceptance in the clinical routine in early breast cancer at low risk [48]. 


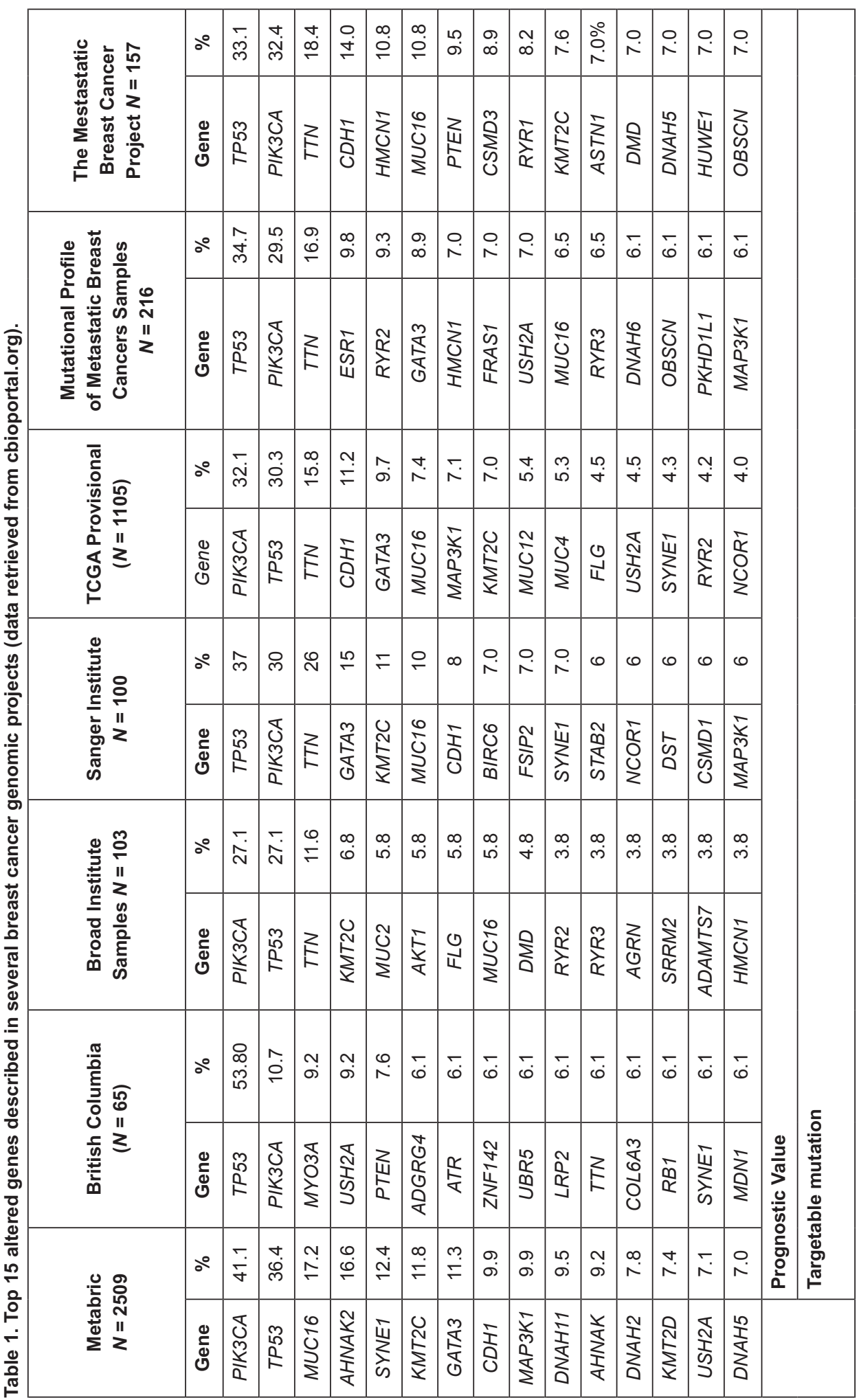




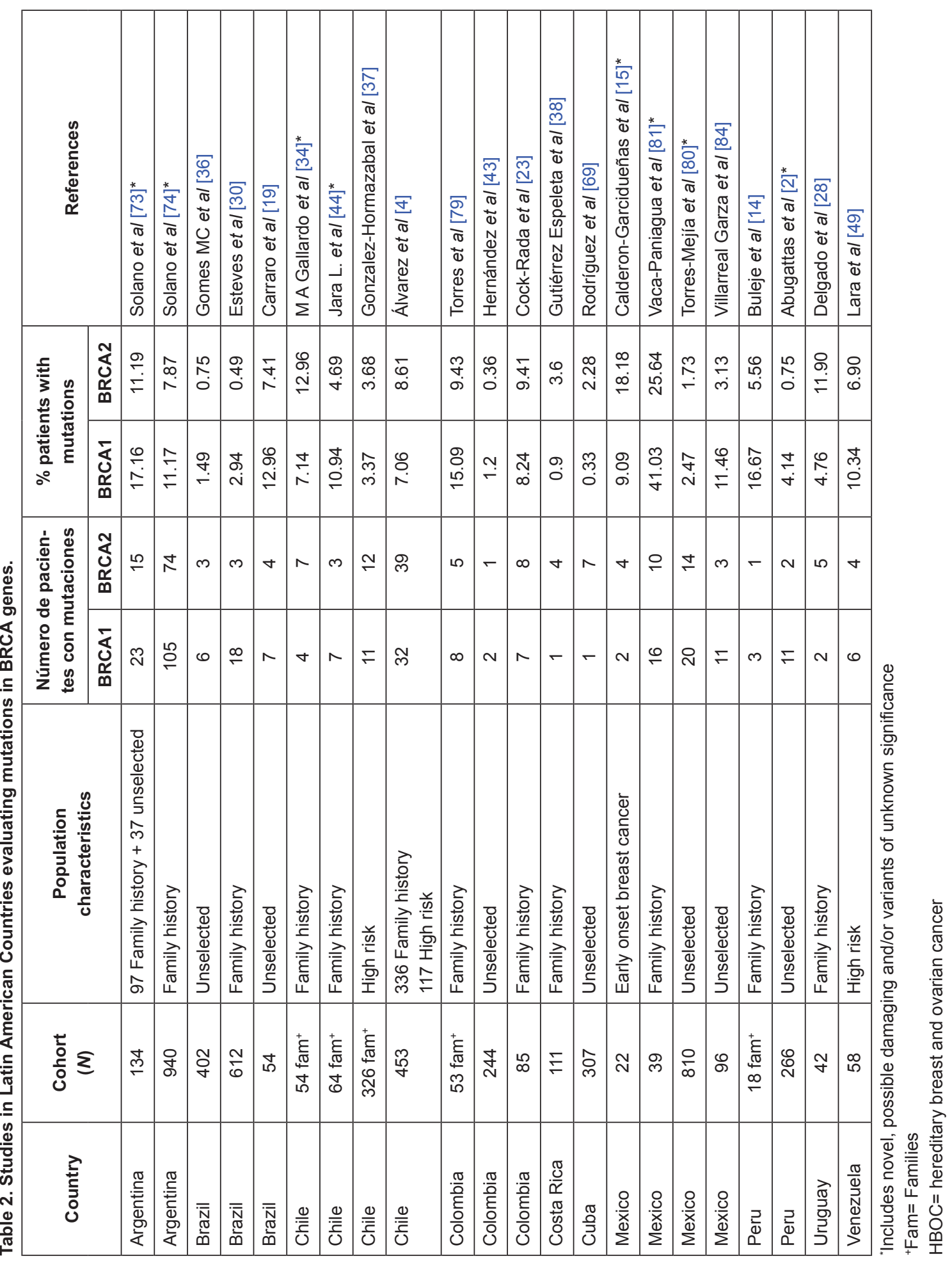


Despite that fact that in LATAM the cost of adjuvant treatment is cheaper than the cost of these platforms to justify a cost-benefit of avoidance of chemotherapy, patient-centred reasons, such as avoidance of unwanted toxicities and better quality of life, have led to the incorporation of these molecular tests in the coverage of private insurance. Oncosalud, the largest pre-paid system in Peru, offers for-free testing with OncotypeDX for their affiliates bearing early-stage hormonal receptor-positive breast tumours at low risk.

Despite several studies conducted in locally advanced breast tumours, there is not a clear indication of molecular testing to select the therapy or to stratify risks in this setting. The MD Anderson Cancer Center conducted a study in LABC, in which Latin American Institutions participated with the intention of developing a genomic predictor (based in cDNA microarrays) of response to neoadjuvant paclitaxel and 5-fluorouracil, doxorubicin and cyclophosphamide [42, 91]. Another Latin American initiative included the development of a three-gene signature based on the expression of CCL5, DDIT4 and POLR1C assessed in residual disease and able to stratify patients in two risk groups and predict the outcome of patients with triple negative breast cancer resistant to neoadjuvant chemotherapy [64]. This study led to other works that improved the understanding of the biology of CCL5 and DDIT4 and contributed to the evaluation of other biomarkers in cancer $[5,26,35,65]$.

\section{Hereditary breast cancer}

Several efforts have been made in Latin American countries to determine the proportion of breast cancer patients bearing germline mutations (Table 2). In unselected patients, BRCA1 and BRCA2 mutations are reported in ranges of $0.3 \%-13 \%$ and $0.75-7.41 \%$, respectively, while in high-risk/hereditary/familiar breast cancer patients, mutations in BRCA1 and BRCA2 were reported in $0.9 \%-16.6 \%$ and $0.49 \%-$ $18.2 \%$, respectively (Table 2).

Frequencies of mutations and the finding of new variants could change according to the technology of sequencing and extension of the gene that will be evaluated (e.g. hotspots versus the entire gene). The work of Vaca-Paniagua et al [81] using pyrosequencing determined a frequency of $41 \%$ of BRCA genes alterations in Mexican patients, where $10 \%$ were known mutations while the rest were novel or variants with unknown clinical significance. On the other hand, Buleje et al [14] in a comprehensive evaluation of $B R C A$ genes, reported a new mutation in the Peruvian population. It indicates the great need for comprehensive profiling of germline mutations in LATAM with the intention to develop more accurate tests, which are customised for this population.

Other genes linked to a high susceptibility described in LATAM patients includes ATM, BARD1, CHECK2, FGFR2, GSTM1, MAP3K1, MTHFR, PALB2, RAD51, TOX3, TP53, XRCC1 and 2q35 [45].

There are several founder mutations identified in LATAM, including BRCA1 del exons 9-12, in Mexico; BRCA1 5382insC and BRCA2 c.156_157insAlu in Brazil and BRCA1 3450del4, A1708E and BRCA2 3034del4, in Colombia [58]. A worldwide study evaluating 29,700 families showed different mutational patterns in BRCA genes in the Latin American/Hispanic population, characterised by fewer mutations in the BRCA1 C-terminal domain and a higher prevalence of the mutation c.3264dup in BRCA2, in contrast to alterations observed in African American and Asian individuals [68].

We need to improve the access to a molecular screening of germline mutations in the region not only for people at high risk of breast and ovarian cancer but also for individuals with other medical conditions.

\section{Potential role of liquid biopsy in breast cancer}

The term liquid biopsy is used to define a sample obtained from biological fluids, such as blood, cerebrospinal fluid, semen and others with the aim to detect and evaluate circulating tumour cells (CTCs), circulating-free DNA (cfDNA), exosomes and other molecules. The study of liquid biopsies has had a great impact in the management of non-small cell lung cancer (NSCLC), which is indicated in cases where a sample of the surgical specimen or a tumour biopsy is not available or insufficient or in patients with progressive or recurrent disease during treatment with tyrosine kinase inhibitors [70]. 
In breast cancer, liquid biopsies have great potential to be incorporated in early diagnosis of this disease. Although in this setting, tests evaluating counts of mutant cfDNA fragments have low detection rates (33\%) [11], counting copy numbers of specific genes could be more useful as a diagnostic test. In a case-control study, breast cancer patients had a higher number of cfDNA copies of PUM1 and RNaseP genes detected in peripheral blood compared with healthy controls. The median count for PUM1 was 4.6 copies/ $\mu \mathrm{L}$ (standard deviation [SD]: 1.96) versus 10.6 copies/ $\mu \mathrm{L}$ (SD: 3.82) and for $R$ NaseP, 3.2 copies $/ \mu \mathrm{L}$ (SD:1.57) versus 7.6 copies $/ \mu \mathrm{L}$ (SD:3.45) for healthy controls versus breast cancer patients, respectively $(p<0.0001$ in both cases) [6].

In the advanced setting (locally advanced/metastatic), $86 \%$ of cases present detectable circulating tumour DNA in the blood [56]. A recent study evaluating 21,807 advanced cancers, in which $16 \%$ were breast tumours, showed the utility of the liquid biopsy to detect targetable mutations in breast cancer patients, for example, alterations in PIK3CA, ESR1 and MYC, FGFR1, HER2 amplifications [89].

Regarding the CTCs count in LABC, it seems not to be related with the response to neoadjuvant chemotherapy [32]; however, in metastatic breast cancer, CTCs provides prognostic information. Detection of $\geq 5$ CTCs in peripheral blood confers a worse prognosis in terms of disease-free survival $(\mathrm{HR}=2.34 ; P=0.0016)$ or overall survival $(\mathrm{OS})(\mathrm{HR}=3.56 ; P=0.0044)[25]$.

In contrast with cfDNA and CTCs, the prognostic value of exosomes has not been defined in breast cancer although it has a wellestablished role in the biology of breast cancer.

The use of liquid biopsies to direct targeted therapy in breast cancer, as well as in other malignant tumours, will depend on the results of large basket trials such as the National Cancer Institute's Molecular Analysis for Therapy Choice, and others, if they demonstrate that treating a targetable mutation in breast cancer is translated to benefit in outcomes.

Despite the fact that the study of liquid biopsies can aid in appropriate patient stratification for targeted therapy and provide important prognostic information, its incorporation in the clinical routine in LATAM, nowadays, is limited.

\section{Immunotherapy in breast cancer}

The value of immunotherapy in breast cancer is not yet well established as is the case for lung cancer, melanoma and other malignancies. The heterogeneity of breast tumours is in part responsible, while the future success of immunotherapy depends on the ability of emerging biomarkers to identify patients who will benefit from the therapy [41].

TNBC cases exhibit a different immunological profile to other breast cancer subtypes with an enriched inflammatory signature and a high expression of the Human Leukocyte Antigen [50]. These characteristics confer to TNBC more opportunities to obtain benefits from immunotherapy in contrast with luminal tumours while HER2 tumours also show potential to get benefit from these drugs [55]. Up to date, one of the better results with an immune checkpoint inhibitor in breast cancer was achieved with atezolizumab in metastatic triple negative breast cancer with a median duration of response of 21 months [29].

On the other hand, in a remarkable study, Zacharakis et al [88] reported the case of a patient treated with tumour-infiltrating lymphocytes (reactive against mutations of the proteins SLC3A2, KIAA0368, CADPS2 and CTSB) plus interleukin-2 and pembrolizumab, achieving the complete durable regression of hormone-sensitive metastatic breast cancer [88].

Unfortunately, there is a lack of immunotherapy studies in our region. Large trials evaluating PD-1/PDL-1 inhibitors in breast cancer are not being conducted in LATAM. Up to date, only one immunotherapy study is active (source: clinicatrials.gov), whose purpose is to evaluate the immunogenicity and safety of dendritic cells, and which is recruiting patients in Colombia (NCT03450044).

\section{High-precision radiotherapy}

The role of radiotherapy (RT) in the management of breast cancer has evolved significantly over the last decades. The addition of RT to conservation surgery significantly reduces the local recurrence rates which translate into a $5 \%$ decrease in breast cancer-specific cancer mortality to 15 years, regardless of lymph node status [92]. 
The treatment of $L A B C$ represents a challenge for radiation oncologists. Despite advances in surgery and systematic therapies, these patients continue to have a high risk of loco-regional recurrences which can lead to severe symptoms, compromised quality of life and distant metastasis. In locally advanced disease, radiation therapy to the chest wall and lymph node stations (supraclavicular, infraclavicular, axillary and internal mammary) associated with post-mastectomy chemotherapy reduces loco-regional recurrences and improves recurrence-free survival and OS. In addition, high-risk patients with large tumours, high histological grade and extensive lymph nodes involvement with radical axillary dissection benefit most from post-mastectomy RT [93-96].

The concept of personalised RT is not new but has evolved in parallel with advances in the identification of the target and the precise administration of the treatment; the technical aspects associated with the inclusion of tumour characteristics in the decision-making process can maximise the risk/ratio in this clinical scenario that requires individualisation and adaptation of treatments.

Innovative radiation delivery techniques such as intensity-modulated radiotherapy, volumetric arc therapy and administered under imageguided radiotherapy have improved the planning and administration of RT to the tumour while minimising the dose delivered to healthy tissues. These techniques not only deliver the radiation with high precision but also diminish the treatment times allowing it to be performed as fast as 1.5 minutes on beam time (Pierce et al, 2002). In addition, in oligometastatic, oligoprogressive or oligorecurrent disease, RT offers highly precise techniques, including intracranial stereotactic radiosurgery and fractionated stereotactic radiation therapy and stereotactic ablative RT or stereotactic body radiation therapy [97].

From the perspective of the radiation oncologist, the spectrum of locally advanced cancer management changes rapidly. The broad understanding of the biological complexities of breast cancer has led to better systemic therapies and targeted therapies which are increasingly available. It is imperative that advanced RT treatments go hand in hand with these efforts in order to provide personalised therapies and improve outcomes in this scenario which is a challenge for treatment.

Also, in the Immuno-oncology era, there are multiples studies trying to address the best combination of target therapy/chemotherapy and immunotherapy in locally advanced and metastatic breast cancer, not all metastatic sites are created equal, most tumours are not innately responsive to checkpoint blockade alone-we must look for immunogenic neoantigen presentation, tumour microenvironment and better patient selection/host features to see how they could interact with each other in order to improve desired outcomes [87].

In the era of personalised RT for the treatment of locally advanced breast cancer, radiation treatments must be adapted to the individual risks of each patient, as well as the intrinsic biology of the tumours.

\section{Precision medicine in medical education}

The World Federation for Medical Education defines medical education as 'a continuum that starts with undergraduate training, continues with postgraduate training and extends with continuing education', with the main objective of 'training professionals with capacity to improve the health of the population'. Levels and contents of Medical Education must be permanently renewed, to adapt to changes, the hyper obsolescence of knowledge, the need to continually change medical knowledge and professional practice [47]. On the other hand, technology has undergone rapid evolution since the remodelling of the landscape of biomedical sciences two decades ago.

Clinical practice has evolved in this way from evidence-based medicine to a custom-tailored therapeutic approach. Nowadays, patients are well informed and have wide access to the latest scientific information, clinical practice guidelines and also to direct-to-consumers genetic tests. Introduction of precision medicine in the medical school curriculum is essential.

To improve the education of physicians prepared for the age of genomic medicine, it is suggested that reforms should be made to the medical curriculum, including making genetics a core competency (like anatomy) and introducing students to computational methods for genomic analysis [53]. In Peru, this necessity has been addressed since 2017 by the ASPEFAM, an association comprised of 27 medical schools from public or private universities.

Regional initiatives for higher education such as the Tuning LATAM project [40] should address the necessity to improve the competencies in precision medicine for undergraduate students at a high standard in order to obtain highly competitive health professionals. 


\section{Challenges for precision medicine in the region: 'the Latin American Genoma'}

The term 'LATAM' was coined in the middle of the 19th century with the geopolitical purpose to designate the territories of the Americas with French, Spanish and Portuguese colonies [67]. Despite the great differences in cultural, ethnic and genetic backgrounds in LATAM, for genomic or clinical research purposes, the single term 'Latin American' or 'Hispanic' is commonly used to designate people living in or migrating from countries in this region.

Several studies have shown different genetic structure according to the geographical distribution in LATAM [85], while in the same country it is possible to observe population groups with great genetic differences. This is the case for Peru, despite the fact that the majority of the population lives on the coast, mostly mestizos; there are several communities in the Andes and in the jungle, with a divergent genetic background, explained by the isolation [71]. Particularities in the genetics of the Peruvian population could explain, for example, higher rates of EGFR mutations seen in NSCLC compared with other Latin American countries (believed to be due to a higher proportion of Asian ancestry in Peru compared with other LATAM countries) [65, 75].

This diverse genetic background has a practical relevance into the interpretation of cancer genome sequencing because of the presence of germline variants in the population, which could be confused with somatic activating mutations of the tumour. The Latin American population has a higher distribution of unique missense variants compared with the European population [39].

Environmental factors could shape the nature of particular cancer and this is responsible for the different epidemiology seen in some cancers in the region. Well-known examples of this environment-epidemiology relationship correspond to the highest incidence of gallbladder cancer in Chile compared to other countries in the region [7]. In addition, Hepatocellular carcinoma in Peru has different epidemiology (earlier onset and related to hepatitis B virus infection) and molecular patterns in contrast with other countries within this region or the world [52].

Regarding breast cancer, in LATAM, there is a higher prevalence of TNBC compared with Caucasian populations [83]. However, it is suggested that the proportion of TNBC which is related to socioeconomic conditions [13], genetic or environmental explanations needs to be explored.

There is a great need for a better genomic characterisation of different cancers in the region at country level and with publicly available data in order to improve the genomic tools for a better risk-stratification and a more precise therapy selection in our LATAM patients.

\section{Future perspectives and conclusion}

'Latin American' or 'Hispanic' are convenient terms used commonly in clinical or genomic research; however, people with different ancestry and genetic background are grouped under this label. In order to improve our approach for precision medicine in cancer, regional genomic initiatives should be initiated and empowered. Although precision medicine in LATAM is often limited to private practice, there is a huge challenge to be faced in making it more inclusive to benefit patients.

\section{References}

1. Abuchacra LD, Alvarado GJ, and Ferretti CN, et al (2012) Relación entre la clasificación según tipos histológicos y subtipos moleculares más frecuentes de carcinoma mamario entre los años 2007 y 2012 en San Miguel de Tucumán, Argentina CIMEL 17 76-91

2. Abugattas J, Llacuachaqui M, and Allende YS, et al (2015) Prevalence of BRCA1 and BRCA2 mutations in unselected breast cancer patients from Peru Clin Genet 88 371-375 https://doi.org/10.1111/cge.12505 PMCID: 4374018

3. Acevedo F, Camus M, and Vial C, et al (2015) Inmunohistoquímica convencional como predictor de respuesta y sobrevida en pacientes con cáncer de mama tratadas con quimioterapia preoperatoria: Experiencia de un centro Rev méd Chile 143 724-732 https://doi.org/10.4067/S0034-98872015000600005 
4. Alvarez C, Tapia T, and Perez-Moreno E, et al (2017) BRCA1 and BRCA2 founder mutations account for $\mathbf{7 8 \%}$ of germline carriers among hereditary breast cancer families in Chile Oncotarget 8 74233-74243 https://doi.org/10.18632/oncotarget.18815 PMID: $\underline{29088781}$ PMCID: $\underline{5650336}$

5. Araujo JM, Ponce J, and Murillo A, et al (2018) Evaluation of circulating free DNA in non-metastatic breast cancer Proc. American Association for Cancer Research Annual Meeting 2018 (Chicago, IL, Philadelphia, PA: AACR) Cancer Res 78(13)

6. Araujo JM, Gomez AC, and Aguilar A, et al (2018) Effect of CCL5 expression in the recruitment of immune cells in triple negative breast cancer Sci Rep 8(1) 4899 https://doi.org/10.1038/s41598-018-23099-7 PMID: 29559701 PMCID: 5861063

7. Are C, Ahmad H, and Ravipati A, et al (2017) Global epidemiological trends and variations in the burden of gallbladder cancer J Surg Oncol 115(5) 580-590 https://doi.org/10.1002/jso.24546 PMID: $\underline{28138977}$

8. Balko JM, Schwarz LJ, and Luo N, et al (2016) Triple-negative breast cancers with amplification of JAK2 at the 9p24 locus demonstrate JAK2-specific dependence Sci Trans/ Med 8(334) 334-353 https://doi.org/10.1126/scitrans/med.aad3001

9. Balko JM, Giltnane JM, and Wang K, et al (2014) Molecular profiling of the residual disease of triple-negative breast cancers after neoadjuvant chemotherapy identifies actionable therapeutic targets Cancer Discov 4(2) 232-245 https://doi.org/10.1158/21598290.CD-13-0286 PMCID: $\underline{3946308}$

10. Banerji S, Cibulskis K, and Rangel-Escareno C, et al (2012) Sequence analysis of mutations and translocations across breast cancer subtypes Nature 486(7403) 405-409 https://doi.org/10.1038/nature11154 PMID: 22722202 PMCID: 4148686

11. Bettegowda C, Sausen M, and Leary RJ, et al (2014) Detection of circulating tumor DNA in early- and late-stage human malignancies Sci Transl Med 6(224) 224 https://doi.org/10.1126/scitranslmed.3007094

12. Bonilla-Sepúlveda OA, Matute-Turízo G, and Severiche C (2015) Clasificación en subtipos intrínsecos de los carcinomas de mama analizados en un centro de patología de Medellín en el año 2011 Rev CES Med 289 35-46

13. Boyle P (2012) Triple-negative breast cancer: epidemiological considerations and recommendations Ann Oncol 23(S6) vi7vi12 https://doi.org/10.1093/annonc/mds187 PMID: 23012306

14. Buleje J, Guevara-Fujita M, and Acosta O, et al (2017) Mutational analysis of BRCA1 and BRCA2 genes in Peruvian families with hereditary breast and ovarian cancer Mol Genet Genomic Med 5 481-494 https://doi.org/10.1002/mgg3.301 PMID: 28944232 PMCID: $\underline{5606899}$

15. Calderón-Garcidueñas AL, Ruiz-Flores P, and Cerda-Flores RM, et al (2005) Clinical follow up of mexican women with early onset of breast cancer and mutations in the BRCA1 and BRCA2 genes Salud Publica Mex 47 110-115 https://doi.org/10.1590/S0036$\underline{36342005000200004}$ PMID: $\underline{15889636}$

16. Camejo N, Gonzalez V, and Castillo C, et al (2011) Survival analysis of breast cancer subtypes assessed by hormone receptors and HER2 tumor expression in Uruguayan women with operable breast cancer J Clin Oncol 29 e21064 https://doi.org/10.1200/ ico.2011.29.15 suppl.e21064

17. Cancer Genome Atlas Network (2012) Comprehensive molecular portraits of human breast tumours Nature 490(7418) 61-70 https://doi.org/10.1038/nature11412 PMID: 23000897 PMCID: 3465532

18. Carey LA, Perou CM, and Livasy CA, et al (2006) Race, breast cancer subtypes, and survival in the Carolina Breast Cancer Study JAMA 295(21) 2492-2502 https://doi.org/10.1001/jama.295.21.2492 PMID: 16757721

19. Carraro DM, Koike Folgueira MAA, and Garcia Lisboa BC, et al (2013) Comprehensive Analysis of BRCA1, BRCA2 and TP53 Germline Mutation and Tumor Characterization: A Portrait of Early-Onset Breast Cancer in Brazil PLoS One 8 e57581 https:// doi.org/10.1371/journal.pone.0057581 PMID: 23469205 PMCID: $\underline{3586086}$

20. Carvalho FM, Bacchi LM, and Pincerato KM, et al (2014) Geographic differences in the distribution of molecular subtypes of breast cancer in Brazil BMC Womens Health 14102 https://doi.org/10.1186/1472-6874-14-102 PMID: 25174527 PMCID: $\underline{4153008}$ 
21. Castaneda CA, Lopez-llasaca M, and Pinto JA, et al (2014) PIK3CA mutations in Peruvian patients with HER2-amplified and triple negative non-metastatic breast cancers Hematol Oncol Stem Cell Ther 7(4) 142-148 https://doi.org/10.1016/j.hemonc.2014.09.007 PMID: 25467032

22. Cheang MC, Chia SK, and Voduc D, et al (2009) Ki67 index, HER2 status, and prognosis of patients with luminal B breast cancer J Natl Cancer Inst 101(10) 736-750 https://doi.org/10.1093/jnci/djp082 PMID: 19436038 PMCID: 2684553

23. Cock-Rada AM, Ossa CA, and Garcia HI, et al (2018) A multi-gene panel study in hereditary breast and ovarian cancer in Colombia Fam Cancer 17 23-30 https://doi.org/10.1007/s10689-017-0004-z

24. The Economist Intelligence Unit Limited (2017) Control del cáncer, acceso y desigualdad en América Latina: Una historia de luces y sombras [http://www.eiuperspectives.economist.com/sites/default/files/images/Cancer_control_access and inequality in Latin America SPANISH.pdf]

25. Cristofanilli M, Hayes DF, and Budd GT, et al (2005) Circulating tumor cells: a novel prognostic factor for newly diagnosed metastatic breast cancer J Clin Oncol 23(7) 1420-1430 https://doi.org/10.1200/JCO.2005.08.140 PMID: 15735118

26. Daizumoto K, Yoshimaru T, and Matsushita Y, et al (2018) A DDX31/Mutant-p53/EGFR axis promotes multistep progression of muscle-invasive bladder cancer Cancer Res 78(9) 2233-2247 https://doi.org/10.1158/0008-5472.CAN-17-2528 PMID: 29440146

27. de Macêdo Andrade AC, Ferreira Júnior CA, and Dantas Guimarães B, et al (2014) Molecular breast cancer subtypes and therapies in a public hospital of northeastern Brazil BMC Womens Health 14110 https://doi.org/10.1186/1472-6874-14-110 PMID: 25216732 PMCID: $\underline{4166019}$

28. Delgado L, Fernández G, and Grotiuz G, et al (2011) BRCA1 and BRCA2 germline mutations in Uruguayan breast and breastovarian cancer families. Identification of novel mutations and unclassified variants Breast Cancer Res Treat 128 $211-218$ https://doi.org/10.1007/s10549-010-1320-2

29. Emens LA, Cruz C, and Eder JP, et al (2018) Long-term clinical outcomes and biomarker analyses of atezolizumab therapy for patients with metastatic triple-negative breast cancer: a phase 1 study. JAMA

30. Esteves VF, Thuler LCS, and Amêndola LC, et al (2009) Prevalence of BRCA1 and BRCA2 gene mutations in families with medium and high risk of breast and ovarian cancer in Brazil Brazilian J Med Biol Res 42 453-457 https://doi.org/10.1590/S0100879X2009000500009

31. Fehrenbacher L, Cecchini RS, and Geyer CE, et al (2018) NSABP B-47 (NRG oncology): Phase III randomized trial comparing adjuvant chemotherapy with adriamycin $(A)$ and cyclophosphamide $(C) \rightarrow$ weekly paclitaxel $(W P)$, or docetaxel $(T)$ and $C$ with or without a year of trastuzumab $(H)$ in women with node-positive or high-risk node-negative invasive breast cancer (IBC) expressing HER2 staining intensity of IHC 1+ or 2+ with negative FISH (HER2-Low IBC) Proc. 2017 San Antonio Breast Cancer Symposium (San Antonio, TX, Philadelphia, PA: AACR) Cancer Res 78(4)

32. Fei F, Du Y, and Di G, et al (2014) Are changes in circulating tumor cell (CTC) count associated with the response to neoadjuvant chemotherapy in local advanced breast cancer? A meta-analysis Oncol Res Treat 37 250-254 https://doi.org/10.1159/000362378 PMID: 24853784

33. Ferlay J, Soerjomataram I, and Ervik M, et al (2013) GLOBOCAN 2012 v1.0, Cancer Incidence and Mortality Worldwide: IARC CancerBase No. 11 (Lyon, France: International Agency for Research on Cancer) [http://globocan.iarc.fr, accessed on day/month/year]

34. Gallardo M, Silva A, and Rubio L, et al (2006) Incidence of BRCA1 and BRCA2 mutations in 54 Chilean families with breast/ovarian cancer, genotype-phenotype correlations Breast Cancer Res Treat 95 81-87 https://doi.org/10.1007/s10549-005-9047-1

35. Givechian KB, Garner C, and Garban H (2018) CAD/POLD2 gene expression is associated with poor overall survival and chemoresistance in bladder urothelial carcinoma Oncotarget 9(51) 29743-29752 https://doi.org/10.18632/oncotarget.25701 PMID: $\underline{30038717}$ PMCID: $\underline{6049856}$ 
36. Gomes MCB, Costa MM, and Borojevic R, et al (2007) Prevalence of BRCA1 and BRCA2 mutations in breast cancer patients from Brazil Breast Cancer Res Treat 103 349-353 https://doi.org/10.1007/s10549-006-9378-6

37. Gonzalez-Hormazabal P, Gutierrez-Enriquez S, and Gaete D, et al (2011) Spectrum of BRCA1/2 point mutations and genomic rearrangements in high-risk breast/ovarian cancer Chilean families Breast Cancer Res Treat 126 705-716 https://doi.org/10.1007/ s10549-010-1170-y

38. Gutiérrez G, Llacuachaqui M, and García-Jiménez L, et al (2012) BRCA1 and BRCA2 mutations among familial breast cancer patients from Costa Rica Clin Genet 82 484-488 https://doi.org/10.1111/j.1399-0004.2011.01774.x

39. Halperin RF, Carpten JD, and Manojlovic Z, et al (2017) A method to reduce ancestry related germline false positives in tumor only somatic variant calling BMC Med Genomics 1061 https://doi.org/10.1186/s12920-017-0296-8 PMID: 29052513 PMCID: 5649057

40. Hanne C (2013) El proyecto Tuning latinoamericano: la experiencia del área de Medicina Rev Hosp Clín Univ Chile 25 19-31

41. Hammerl D, Smid M, and Timmermans AM, et al (2018) Breast cancer genomics and immuno-oncological markers to guide immune therapies Semin Cancer Biol 52(Pt 2) 178-188 https://doi.org/10.1016/j.semcancer.2017.11.003

42. Hatzis C, Pusztai L, and Valero V, et al (2011) A genomic predictor of response and survival following taxane-anthracycline chemotherapy for invasive breast cancer JAMA 305(18) 1873-1881 https://doi.org/10.1001/jama.2011.593

43. Hernández JEL, Llacuachaqui M, and Palacio GV, et al (2014) Prevalence of BRCA1 and BRCA2 mutations in unselected breast cancer patients from Medellín, Colombia Hered Cancer Clin Pract 1211 https://doi.org/10.1186/1897-4287-12-11

44. Jara L, Ampuero S, and Santibáñez E, et al (2006) BRCA1 and BRCA2 mutations in a South American population Cancer Genet Cytogenet 166 36-45 https://doi.org/10.1016/j.cancergencyto.2005.08.019

45. Jara L, Morales S, and de Mayo T, et al (2017) Mutations in BRCA1, BRCA2 and other breast and ovarian cancer susceptibility genes in Central and South American populations Biol Res 50(1) 35 https://doi.org/10.1186/s40659-017-0139-2

46. Justo N, Wilking N, and Jönsson B, et al (2013) A review of breast cancer care and outcomes in Latin America Oncologist 18(3) 248-256 https://doi.org/10.1634/theoncologist.2012-0373

47. Karle H (2006) Global standards and accreditation in medical education: a view from the WFME Acad Med 81(12) S43-S48 https://doi.org/10.1097/01.ACM.0000243383.71047.c4

48. Kwa M, Makris A, and Esteva FJ (2017) Clinical utility of gene-expression signatures in early stage breast cancer Nat Rev Clin Oncol 14(10) 595-610 https://doi.org/10.1038/nrclinonc.2017.74

49. Lara K, Consigliere N, and Pérez J, et al (2012) BRCA1 and BRCA2 mutations in breast cancer patients from Venezuela Biol Res 45 117-130 https://doi.org/10.4067/S0716-97602012000200003

50. Liu Z, Li M, and Jiang Z, et al (2018) A Comprehensive Immunologic Portrait of Triple-Negative Breast Cancer Trans/ Oncol 11(2) 311-329 https://doi.org/10.1016/j.tranon.2018.01.011 PMCID: $\underline{5884188}$

51. Mangone FR, Bobrovnitchaia IG, and Salaorni S, et al (2012) PIK3CA exon 20 mutations are associated with poor prognosis in breast cancer patients Clinics (Sao Paulo) 67(11) 1285-1290 https://doi.org/10.6061/clinics/2012(11)11

52. Marchio A, Bertani S, and Rojas T, et al (2014) A peculiar mutation spectrum emerging from young peruvian patients with hepatocellular carcinoma PLoS One 9(12) e114912 https://doi.org/10.1371/journal.pone.0114912

53. Mc Grath S and Ghersi D (2016) Building towards precision medicine: empowering medical professionals for the next revolution BMC Med Genomics 9(1) 23 https://doi.org/10.1186/s12920-016-0183-8

54. Meiss RP, Novelli JE, and Gago FE, et al (2018) Breast cancer in Argentina: feasibility for the implementation of the new TNM staging system 2018 in a middle-income Country J Can Epi Treat 2 4-12 https://doi.org/10.24218/icet.2018.20

55. Nathan MR and Schmid P (2018) The emerging world of breast cancer immunotherapy Breast 37 200-206 https://doi.org/10.1016/j. breast.2017.05.013 
56. Odegaard JI, Vincent JJ, and Mortimer S, et al (2018) Validation of a plasma-based comprehensive cancer genotyping assay utilizing orthogonal tissue- and plasma-based methodologies Clin Cancer Res https://doi.org/10.1158/1078-0432.CCR-17-3831

57. Ortiz AP, Frías O, and Pérez J, et al (2013) Breast cancer molecular subtypes and survival in a hospital-based sample in Puerto Rico Cancer Med 2 343-350 https://doi.org/10.1002/cam4.78

58. Ossa CA and Torres D (2016) Founder and recurrent mutations in BRCA1 and BRCA2 genes in Latin American Countries: state of the art and literature review Oncologist 21 832-839 https://doi.org/10.1634/theoncologist.2015-0416

59. Parker JS, Mullins M, and Cheang MC, et al (2009) Supervised risk predictor of breast cancer based on intrinsic subtypes $J$ Clin Oncol 27(8) 1160-1167 https://doi.org/10.1200/JCO.2008.18.1370

60. Pereira B, Chin SF, and Rueda OM, et al (2016) The somatic mutation profiles of 2,433 breast cancers refines their genomic and transcriptomic landscapes Nat Commun 711479 https://doi.org/10.1038/ncomms11479

61. Perez V, Maldonado-Mtz HA, and De León D, et al (2012) Breast carcinoma in Mexican women, molecular subtypes using immunohistochemical surrogate markers $E J$ Cancer 14(S1)

62. Pérez-Rodríguez G (2015) Prevalencia de subtipos por inmunohistoquímica del cáncer de mama en pacientes del Hospital General Regional 72, Instituto Mexicano del seguro social Cirugía y Cirujanos 83 193-198 https://doi.org/10.1016/j.circir.2015.05.003

63. Perou CM, Sørlie T, and Eisen MB, et al (2000) Molecular portraits of human breast tumours Nature 406(6797) 747-752 Repeated observation of breast tumor subtypes in independent gene expression data sets Proc Natl Acad Sci USA 2003 100(14) 8418-8423 https://doi.org/10.1038/35021093

64. Pinto JA, Araujo J, and Cardenas NK, et al (2016) A prognostic signature based on three-genes expression in triple-negative breast tumours with residual disease NPJ Genom Med 115015 https://doi.org/10.1038/npjgenmed.2015.15

65. Pinto JA, Mas LA, and Gomez HL (2017) High epidermal growth factor receptor mutation rates in peruvian patients with nonsmall-cell lung cancer: is it a matter of Asian ancestry? J Glob Oncol 3(4) 429-430 https://doi.org/10.1200/JG0.2016.008201 PMID: 28831453 PMCID: $\underline{560464}$

66. Pinto JA, Rolfo C, and Raez LE, et al (2017) In silico evaluation of DNA Damage Inducible Transcript 4 gene (DDIT4) as prognostic biomarker in several malignancies Sci Rep 7(1) 1526 https://doi.org/10.1038/s41598-017-01207-3

67. Quijano A (2000) Coloniality of power and eurocentrism in Latin America Internat Sociol 15 215-232 https://doi. org/10.1177/0268580900015002005

68. Rebbeck TR, Friebel TM, and Friedman E, et al (2018) Mutational spectrum in a worldwide study of 29,700 families with BRCA1 or BRCA2 mutations Hum Mutat 39(5) 593-620 https://doi.org/10.1002/humu.23406

69. Rodriguez RC, Esperon AA, and Ropero R, et al (2008) Prevalence of BRCA1 and BRCA2 mutations in breast cancer patients from Cuba Fam Cancer 7 275-279 https://doi.org/10.1007/s10689-008-9187-7

70. Rolfo C, Mack PC, and Scagliotti GV, et al (2018) IASLC statement paper: liquid biopsy for advanced non-small cell lung cancer (NSCLC) J Thorac Oncol https://doi.org/10.1016/j.jtho.2018.05.030

71. Sandoval JR, Lacerda DR, and Acosta O, et al (2016) The genetic history of peruvian quechua-lamistas and chankas: uniparental DNA patterns among autochthonous amazonian and andean populations Ann Hum Genet 80(2) 88-101 https://doi. org/10.1111/ahg. 12145

72. Serrano-Gomez SJ, Sanabria-Salas MC, and Hernández-Suarez G, et al (2016) High prevalence of luminal B breast cancer intrinsic subtype in Colombian women Carcinogenesis 37 669-676 https://doi.org/10.1093/carcin/bgw043 PMID: 27207651 PMCID: 4936382

73. Solano A, Aceto G, and Delettieres D, et al (2012) BRCA1 And BRCA2 analysis of Argentinean breast/ovarian cancer patients selected for age and family history highlights a role for novel mutations of putative south-American origin Springerplus 120 https://doi.org/10.1186/2193-1801-1-20 
74. Solano AR, Cardoso FC, and Romano V, et al (2017) Spectrum of BRCA1/2 variants in 940 patients from Argentina including novel, deleterious and recurrent germline mutations: impact on healthcare and clinical practice Oncotarget 8 60487-60495 https://doi.org/10.18632/oncotarget.10814 PMCID: $\underline{5601155}$

75. Soraas $L$ and Stebbing $J(2018)$ Geographic variation in EGFR mutation frequency in lung adenocarcinoma may be explained by Interethnic Genetic Variation J Thorac Oncol 13(3) 454-458 https://doi.org/10.1016/j.jtho.2017.11.128

76. Sorlie T, Tibshirani R, and Parker J, et al (2003) Repeated observation of breast tumor subtypes in independent gene expression data sets Proc Natl Acad Sci USA 100(14) 8418-8423 https://doi.org/10.1073/pnas.0932692100 PMID: 12829800 PMCID: 166244

77. Srur-Rivero N and Cartin-Brenes M (2014) Breast cancer characteristics and survival in a hispanic population of costa rica Breast Cancer : Basic and Clinical Research 8 103-108

78. Tong $\mathrm{Y}$, Chen $\mathrm{X}$, and Fei $\mathrm{X}$, et al (2018) Can breast cancer patients with HER2 dual-equivocal tumours be managed as HER2negative disease? Eur J Cancer 89 9-18 https://doi.org/10.1016/j.ejca.2017.10.033

79. Torres D, Rashid MU, and Gil F, et al (2007) High proportion of BRCA1/2 founder mutations in hispanic breast/ovarian cancer families from Colombia Breast Cancer Res Treat 103 225-232 https://doi.org/10.1007/s10549-006-9370-1

80. Torres-Mejía G, Royer R, and Llacuachaqui M, et al (2015) Recurrent BRCA1 and BRCA2 mutations in Mexican women with breast cancer Cancer Epidemiol Biomarkers Prev 24 498-505 https://doi.org/10.1158/1055-9965.EPI-13-0980 PMCID: 4495576

81. Vaca-Paniagua F, Alvarez-Gomez RM, and Fragoso-Ontiveros V, et al (2012) Full-exon pyrosequencing screening of BRCA germline mutations in Mexican women with inherited breast and ovarian cancer PLoS One 7 e37432 https://doi.org/10.1371/journal. pone.0037432

82. Vallejos CS, Gómez HL, and Cruz WR, et al (2010) Breast cancer classification according to immunohistochemistry markers: Subtypes and association with clinicopathologic variables in a peruvian hospital database Clin Breast Cancer 10 294-300 https://doi.org/10.3816/CBC.2010.n.038 PMID: 20705562

83. Vallejos CS, Gómez HL, and Cruz WR, et al (2010) Breast cancer classification according to immunohistochemistry markers: subtypes and association with clinicopathologic variables in a peruvian hospital database Clin Breast Cancer 10(4) 294-300 https://doi.org/10.3816/CBC.2010.n.038

84. Villarreal-Garza C, Alvarez-Gómez RM, and Pérez-Plasencia C, et al (2015) Significant clinical impact of recurrent BRCA1 and BRCA2 mutations in Mexico Cancer 121 372-378 https://doi.org/10.1002/cncr.29058

85. Wang S, Ray N, and Rojas W, et al (2008) Geographic patterns of genome admixture in Latin American Mestizos PLoS Genet 4(3) e1000037 https://doi.org/10.1371/journal.pgen.1000037

86. Yábar A, Meléndez R, and Muñoz S, et al (2017) Effect of Ki-67 assessment in the distribution of breast cancer subtypes: Evaluation in a cohort of Latin American patients Mol Clin Oncol 6(4) 503-509 https://doi.org/10.3892/mco.2017.1185

87. Ye JC and Formenti SC (2018) Integration of radiation and immunotherapy in breast cancer-treatment implications Breast 38 66-74 https://doi.org/10.1016/j.breast.2017.12.005

88. Zacharakis $\mathrm{N}$, Chinnasamy $\mathrm{H}$, and Black $\mathrm{M}$, et al (2018) Immune recognition of somatic mutations leading to complete durable regression in metastatic breast cancer Nat Med 24(6) 724-730 https://doi.org/10.1038/s41591-018-0040-8

89. Zill OA, Banks KC, and Fairclough SR, et al (2018) The landscape of actionable genomic alterations in cell-free circulating tumor DNA from 21,807 advanced cancer patients Clin Cancer Res https://doi.org/10.1158/1078-0432.CCR-17-3837

90. Giacomazzi J, Graudenz MS, and Osorio CA et al (2014) Prevalence of the TP53 p.R337H mutation in breast cancer patients in Brazil PLoS One 9(6) https://doi.org/10.1371/journal.pone.0099893 
91. Hess KR, Anderson K, and Symmans WF et al (2006) Pharmacogenomic predictor of sensitivity to preoperative chemotherapy with paclitaxel and fluorouracil, doxorubicin, and cyclophosphamide in breast cancer J Clin Oncol 24(26) 4236-44

92. Clarke M, Collins R, and Darby S et al (2005) Effects of radiotherapy and of differences in the extent of surgery for early breast cancer on local recurrence and 15-year survival: an overview of the randomised trials Lancet 366(9503) 2087-106

93. Overgaard M, Hansen PS, and Overgaard J et al 1997 Postoperative radiotherapy in high-risk premenopausal women with breast cancer who receive adjuvant chemotherapy. Danish Breast Cancer Cooperative Group 82b Trial N Engl J Med 337(14) 949-55.

94. Overgaard M, Jensen MB, and Overgaard J et al (1999) Postoperative radiotherapy in high-risk postmenopausal breast-cancer patients given adjuvant tamoxifen: Danish Breast Cancer Cooperative Group DBCG 82c randomised trial Lancet 353(9165) 1641-8

95. Ragaz J, Olivotto IA, and Spinelli JJ et al (2005) Locoregional radiation therapy in patients with high-risk breast cancer receiving adjuvant chemotherapy: 20-year results of the British Columbia randomized trial J Natl Cancer Inst 97(2) 116-26

96. Recht A, Edge SB, and Solin LJ et al (2001) Postmastectomy radiotherapy: clinical practice guidelines of the American Society of Clinical Oncology J Clin Oncol 19(5) 1539-69

97. Correa RJ, Salama JK, and Milano MT et al (2016) Stereotactic body radiotherapy for oligometastasis: opportunities for biology to guide clinical management Cancer J 22(4) 247-56 https://doi.org/10.1097/PPO.0000000000000202 